\title{
O RISCO DO USO DE DROGAS NO TRABALHO PORTUÁRIO: ESTUDO NO EXTREMO SUL DO BRASIL ${ }^{a}$
}

\author{
The Risk of the Use of Drugs in the Harbour Work: \\ Study in the Southern Extreme of Brazil \\ El Riesgo del Uso de Drogas en el Trabajo Portuario: \\ Estudio en el Extremo Sur del Brasil
}

\author{
Jorgana Fernanda de Souza Soares ${ }^{1}$ \\ Maria Cristina Flores Soares ${ }^{4}$
}

\author{
Marta Regina Cezar-Vaz ${ }^{2}$ \\ Valdecir Zavarese da Costa ${ }^{5}$
}

Letícia da Silveira Cardoso ${ }^{3}$

Marlise Capa Verde de Almeida ${ }^{6}$

\section{Resumo}

Este é um estudo quantitativo, exploratório e descritivo. Objetivou identificar a realidade do uso de drogas entre os trabalhadores portuários avulsos no microambiente portuário, no extremo sul do Brasil. A amostra constituiu-se de 306 trabalhadores. Os dados foram coletados através de entrevista estruturada e individual e analisados quantitativamente. Dos participantes, 43,14\% responderam que seus colegas já trabalharam sob o efeito de drogas, e as mais utilizadas foram o álcool $(94,70 \%)$ e a maconha (77,27\%). 0 motivo apontado com maior freqüência para o uso foi a dependência (40,15\%). 0 conhecimento da realidade do usuário de drogas e a preocupação com o uso em ambientes de trabalho tornam-se ferramentas importantes para o enfermeiro, posicionando-o como colaborador e parceiro na sensibilização dos indivíduos para a diminuição dos riscos decorrentes do uso de drogas na vida do trabalhador e no ambiente de trabalho.

Palavras-chave: Drogas llícitas. Risco. Ambiente de Trabalho. Enfermagem.

\begin{abstract}
This is a quantitative, exploratory and descriptive study. It aimed at identifying the reality of drug usage among the Port Workers at the port environment, in the southern extreme of Brazil. The sample consisted of 306 workers. The data was collected through structured, individual interview and were quantitatively analyzed. Among the participants, 43,14\% answered that their workmates had already worked under the effect of drugs and the mostly used were alcohol $(94,70 \%)$ and marijuana $(77,27 \%)$. The most mentioned reason for the use was the addiction $(40,15 \%)$. The knowledge of the reality of the drug user and the concern with the use at working environments, become important tools for the nurse, positioning it as a collaborator and partner in the sensibility of the individuals for the reduction of risks which result from the use of drugs in the life of the worker as well as in the work environment.
\end{abstract}

Keywords:

Street Drugs. Risk. Working Environment. Nursing.

\section{Resumen}

Esto es un estudio cuantitativo, exploratorio y descriptivo. Objetiva identificar la realidad del uso de drogas entre los trabajadores portuarios autónomos en el micro ambiente portuario, en la extremidad del sur del Brasil. La muestra consistió en 306 trabajadores. Los datos fueran recogidos a través de entrevista estructurada, individual y analizada de modo cuantitativo. De los participantes, $43.14 \%$ habían contestado a que sus colegas habían trabajado sobre el efecto de drogas y las más utilizadas fueron el alcohol (94.70\%) y la marihuana $(77.27 \%)$. La razón apuntada con mayor frecuencia fue la dependencia (40.15\%). El conocimiento de la realidad del usuario de drogas y la preocupación con el uso en ambientes de trabajo, se convierten en herramientas importantes para el enfermero, localizando lo como colaborador y compañero en la sensibilización de los individuos para la reducción de los riesgos consecuentes del uso de drogas en la vida del trabajador y en el ambiente de trabajo.

Palabras clave:

Drogas llícitas. Riesgo. Ambiente de Trabajo. Enfermería. 


\section{INTRODUÇÃO}

0 presente trabalho identifica a existência do risco à saúde e à segurança individual e de colegas dos trabalhadores portuários avulsos (TPAs), da ação de trabalhar sob efeito de algumas drogas (álcool, maconha, cocaína e crack), em um Porto localizado no extremo sul do Brasil. Os TPAs representam um grupo de trabalhadores que prestam serviços às operadoras portuárias, sem vínculo empregatício, através da solicitação ao Órgão Gestor de Mão-de-Obra do Trabalho Portuário Avulso (OGMO). Estes trabalhadores desenvolvem as atividades de capatazia (carga/descarga de produtos em terra); estiva (carga/ descarga de produtos a bordo das embarcações); conferência de carga (conferência dos produtos embarcados/desembarcados); conserto de carga (conserto da embalagem das mercadorias que sofreram avarias); vigilância de embarcações (vigilância da entrada/saída de pessoas e mercadorias da embarcação) e trabalhos em bloco (reparo das embarcações) ${ }^{1}$.

0 uso de drogas sempre esteve presente na história da humanidade, sendo visível em vários contextos, e são utilizadas com objetivos distintos: rituais, comemorações, cultos religiosos, alivio da dor, prazer e como forma de vivência de experiências desconhecidas, tendo também o significado de desregramento, contestação, ameaça, poder e desqualificação². 0 consumo de drogas apresenta em cada sociedade especificidades próprias, já que o consumo condiciona e é condicionado pelos costumes nela encontrados ${ }^{3}$, podendo-se dizer que "a utilização de drogas lícitas e ilícitas permeia a cultura da adolescência à velhice e, no caso do Brasil, notadamente por meio do consumo de álcool, fumo e maconha"::708.

A redução de danos, que se constitui como o conjunto de ações que objetiva a diminuição de danos oriundos do uso/ abuso de drogas ${ }^{5}$, parte das premissas de que inexistiram sociedades alheias às drogas e de diminuir os danos por elas ocasionados, objetivando maximizar o alívio e bem-estar a indivíduos ou coletivos ${ }^{6}$. Na redução de danos, torna-se significativa a participação do profissional enfermeiro, pois, entre os trabalhadores em saúde, estes são os que possuem maior contato com as pessoas que procuram os serviços de saúde e apresentam um grande potencial para reconhecer a problemática relacionada ao consumo de drogas e desenvolver a assistência condizente com a necessidade de cada indivíduo². Além disso, torna-se imprescindível avaliar o enfermeiro como um recurso humano relevante no trabalho com o usuário de drogas, inclusive pelo seu importante papel na comunicação com diferentes grupos na sociedade, desde crianças até idosos ${ }^{7}$.

Nesta função desenvolvida pelo enfermeiro na comunicação em diversas coletividades, torna-se necessário conhecer a dimensão do uso de drogas nos mais distintos cenários, para que seja possibilitado a este profissional o entendimento sobre os indivíduos aos quais ele presta cuidado. É reconhecer que a questão não é a droga em si, mas a relação estabelecida pelo indivíduo com ela, que influencia e é influenciada pelas interações sociais ${ }^{4}$. Assim, pode-se admitir que o cuidado de enfermagem se trata do encontro com o outro, ou seja, com um sujeito que possui uma história, percorreu um caminho, possui sonhos e desejos, (des) crenças, valores, conhecimentos e expectativas ${ }^{2}$, bem como distintas funç̃oes no mercado de trabalho. Neste sentido, o profissional enfermeiro deve atentarse aos ambientes de trabalho, visto que os problemas referentes ao uso de drogas afetam a segurança do trabalhador ${ }^{8}$.

0 enfermeiro necessita conhecer o problema do uso de drogas no ambiente portuário para que, interdisciplinarmente, possa elaborar estratégias para a minimização deste risco no porto, por se entender que este contexto é uma área de risco, visto que o risco de acidentes é constante neste cenário ${ }^{1}$. Existem ambientes insalubres, com cargas químicas e radioativas sendo movimentadas; tudo no porto é grande e pesado, porque as cargas não são movimentadas em quilos, mas sim em toneladas. Além disso, existem os fatores de risco físicos (ruídos, vibrações, umidade), químicos (gases e poeiras) e ergonômicos (posturas inadequadas), e os TPAs e outros que tenham atribuições legais nos portos estão cercados pelo perigo ${ }^{9}$. Neste sentido, este estudo objetivou identificar a realidade do uso de drogas entre os TPAs; as drogas utilizadas com maior freqüência; bem como o motivo para a utilização destas substâncias.

\section{MÉTODO}

Este é um estudo transversal, exploratório e descritivo, com abordagem quantitativa dos dados, realizado em um ambiente portuário no extremo sul do Brasil com TPAs.

A população efetiva de TPAs no período do estudo foi de 758 trabalhadores, conforme o obtido junto ao OGMO.

Inicialmente, foi realizado um diagnóstico situacional sobre o conhecimento dos TPAs dos riscos presentes em seu ambiente de trabalho com 30 TPAs, em virtude da indisponibilidade de dados acerca do objeto do estudo.

A partir do diagnóstico situacional, a amostra foi calculada em 306 TPAs. Para este cálculo, utilizou-se o nível de confiança de $95 \%$, com a prevalência de conhecimento dos riscos à saúde estimada em $93 \pm 3 \%$, considerando-se $10 \%$ de perdas.

A entrevista estruturada utilizada para a coleta dos dados foi construída a partir dos resultados obtidos no diagnóstico situacional, complementada pela revisão de literatura e observações espontâneas dos pesquisadores no porto. A entrevista foi composta por questões em escala nominal (escolha simples), na qual os respondentes eram solicitados a escolher uma das opções listadas pelos pesquisadores.

0 estudo piloto foi realizado com o intuito de averiguar e adaptar as questões da entrevista. Realizou-se o teste á de Crombach, para medir a fidedignidade da mesma, e o resultado obtido foi de 0,73 para a parte do instrumento composta por escala nominal, utilizada neste trabalho, em consonância com o disposto na literatura ${ }^{10}$.

A coleta dos dados foi realizada no período compreendido entre o primeiro e o segundo semestre de 2006, nas proximidades dos locais onde ocorre a escalação dos trabalhadores para o turno de trabalho. Participaram da pesquisa os TPAs que haviam se apresentado para concorrer por uma oportunidade de trabalho no turno.

A entrevista identificou as características sóciodemográficas compreendidas por sexo, idade, tempo de atuação no setor, grau de instrução, estado civil, cor e rendimento 
financeiro. Os participantes foram ainda questionados se seus colegas já trabalharam sob efeito de alguma (s) droga (s), a identificação das mesmas e o motivo para o uso. Decidiu-se optar por questionar se um colega dos participantes da pesquisa trabalhou sob o efeito de drogas, na tentativa de evitar respostas negativas, porque esta negação está atrelada ao receio de haver uma investigação, em virtude de a política antidrogas brasileira ter 0 caráter punitivo ${ }^{11}$. Esta decisão vincula-se também à própria característica do trabalho portuário, na particularidade dos TPAs, o qual possui um tempo de convivência que permite que um trabalhador possua conhecimento suficiente acerca do colega para apontar o uso de drogas no ambiente coletivo de trabalho.

\section{RESULTADOS}

Os dados são apresentados através da distribuição de freqüência simples e analisados quantitativamente.

Quanto aos aspectos éticos da pesquisa, respeitando a resolução do CNS 196/96, foi solicitado e obtido o consentimento do OGMO responsável pelos TPAs. 0 trabalho foi aprovado pelo Comitê de Ética em Pesquisa na Área da Saúde da Fundação Universidade Federal do Rio Grande (Processo n²3116.6779/2005-98), e foi utilizado o consentimento livre e esclarecido do participante, o qual foi obtido previamente à entrevista, sendo assinado em duas vias, uma delas permanecendo com a entrevistadora para arquivamento junto ao processo da pesquisa e a outra, com o participante.

Tabela 1:

Dados das características sócio-econômicas dos TPAs entrevistados.

\begin{tabular}{|c|c|c|}
\hline Variável & $N(306)^{*}$ & $\%$ \\
\hline \multicolumn{3}{|l|}{ Idade } \\
\hline $19-29$ anos & 35 & 11,44 \\
\hline $29-39$ anos & 77 & 25,16 \\
\hline $39-49$ anos & 85 & 27,78 \\
\hline $49-59$ anos & 98 & 32,03 \\
\hline $59-69$ anos & 11 & 3,59 \\
\hline \multicolumn{3}{|l|}{ Tempo de trabalho portuário } \\
\hline$<$ de 02 anos & 07 & 2,29 \\
\hline $02-05$ anos & 52 & 16,99 \\
\hline $05-10$ anos & 12 & 3,92 \\
\hline $10-20$ anos & 95 & 31,05 \\
\hline $20-35$ anos & 120 & 39,22 \\
\hline$>35$ anos & 20 & 6,54 \\
\hline \multicolumn{3}{|l|}{ Rendimento financeiro** } \\
\hline Menos de 02 salários mínimos & 15 & 4,90 \\
\hline 02 - 05 salários mínimos & 123 & 40,20 \\
\hline 05 - 10 salários mínimos & 78 & 25,49 \\
\hline > 10 salários mínimos & 78 & 25,49 \\
\hline Ignorado & 12 & 3,92 \\
\hline \multicolumn{3}{|l|}{ Grau de Instrução } \\
\hline Analfabeto & 02 & 0,65 \\
\hline Ensino Fundamental Incompleto & 110 & 35,95 \\
\hline Ensino Fundamental Completo & 55 & 17,98 \\
\hline Ensino Médio Incompleto & 34 & 11,11 \\
\hline Ensino Médio Completo & 88 & 28,76 \\
\hline Ensino Superior Incompleto, Completo, Pós-graduação & 17 & 5,56 \\
\hline \multicolumn{3}{|l|}{ Estado civil } \\
\hline Solteiro & 87 & 28,43 \\
\hline Casado/União Consensual & 174 & 56,87 \\
\hline Separado/Desquitado/Divorciado & 40 & 13,07 \\
\hline Viúvo & 05 & 1,63 \\
\hline \multicolumn{3}{|l|}{ Cor } \\
\hline Branco & 177 & 57,84 \\
\hline Preto & 50 & 16,34 \\
\hline Amarelo & 01 & 0,33 \\
\hline Pardo & 57 & 18,63 \\
\hline Indígena & 21 & 6,86 \\
\hline
\end{tabular}

*Subtotal diferente para a variável rendimento financeiro, com 12 (3,92\%) indivíduos que se recusaram a responder ao questionamento. **0 salário mínimo vigente no período da elaboração do projeto (segundo semestre de 2005) era de $\mathrm{R} \$ 300,00$. 
A Tabela 1 apresenta as características sócio-demográficas dos trabalhadores entrevistados. Identifica-se a totalidade do sexo masculino, predominando a faixa etária entre 49 e 58 anos (32,03\%). Otempo de trabalho portuário, com maior freqüência $(39,22 \%)$, encontra-se dentro do período de 20 a 34 anos.

Quanto aos rendimentos financeiros, $40,20 \%$ recebem entre dois a cinco salários mínimos, e a maioria dos TPAs entrevistados $(35,95 \%)$ possui o ensino fundamental incompleto. A maioria declarou ser casada ou viver em união consensual $(56,87 \%)$ e se autodeclarou como branca $(57,84 \%)$.

Dos 306 TPAs entrevistados, conforme se pode observar na Tabela 2, 43,14\% responderam que os seus colegas trabalharam sob efeito de drogas, $46,73 \%$, que seus colegas não o fizeram, e 10,13\% não responderam ao questionamento.

\section{Tabela 2:}

Respostas dos 132 entrevistados à questão de os colegas terem trabalhado sob efeito de drogas.

\begin{tabular}{cc}
\hline Respostas & $\begin{array}{c}\text { \% da declaração sobre se os colegas } \\
\text { dos TPAs entrevistados trabalharam } \\
\text { sob o efeito de drogas }(\mathbf{n})\end{array}$ \\
\hline Sim & $43,14(132)$ \\
Não & $46,73(143)$ \\
Não responderam & $10,13(31)$ \\
\hline
\end{tabular}

Na Tabela 3, podem-se visualizar as drogas utilizadas pelos colegas de trabalho dos 132 TPAs que responderam que estes trabalharam sob o efeito de drogas. Ainda na Tabela 2, observa-se que as drogas mais utilizadas foram o álcool e a maconha, de acordo com, respectivamente, $94,70 \%$ e $77,27 \%$ dos respondentes. Pode-se visualizar também, em consonância com os respondentes, o uso de cocaína $(48,48 \%)$ e crack $(22,73 \%)$.

\section{Tabela 3:}

Drogas sob cujo efeito trabalharam os colegas dos 132 entrevistados, segundo estes.

\begin{tabular}{ccccc}
\hline Droga & \multicolumn{3}{c}{$\begin{array}{c}\text { \% das drogas sob cujo efeito trabalharam } \\
\text { os colegas dos entrevistados (N 132) }\end{array}$} \\
\hline & Sim (n) & Não $(\mathrm{n})$ & Não responderam (n) \\
Álcool & $94,70(125)$ & $2,27(03)$ & $3,03(04)$ \\
Maconha & $77,27(102)$ & $15,91(21)$ & $6,82(09)$ \\
Cocaína & $48,48(64)$ & $37,88(50)$ & $13,64(18)$ \\
Crack & $22,73(30)$ & $60,60(80)$ & $16,67(22)$ \\
\hline
\end{tabular}

$\mathrm{Na}$ Tabela 4, podem-se observar os motivos referidos pelos respondentes para o uso de drogas por seus colegas. 0 motivo mais freqüente foi a dependência, conforme $40,15 \%$ dos trabalhadores que responderam à questão. Visualiza-se, ainda, que os motivos do uso de drogas pelos colegas dos respondentes foram o prazer $(16,67 \%)$, para diminuir a fadiga no trabalho $(8,33 \%)$, para ter coragem para realizar o trabalho $(4,55 \%)$, e outros $(18,18 \%)$.
Tabela 4:

Motivo do uso de drogas pelos 132 colegas dos TPAs entrevistados.

\begin{tabular}{cc}
\hline $\begin{array}{c}\text { Motivo do uso de drogas pelos } \\
\text { colegas dos TPAs entrevistados }\end{array}$ & $\begin{array}{c}\text { \% do motivo do uso de } \\
\text { drogas pelos colegas dos } \\
\text { TPAs entrevistados (n) }\end{array}$ \\
\hline Diminuir a fadiga & $8,33(11)$ \\
Ter coragem para realizar o trabalho & $4,55(06)$ \\
Dependência & $40,15(53)$ \\
Prazer & $16,67(22)$ \\
Outros & $18,18(24)$ \\
Não respondeu & $12,12(16)$ \\
\hline
\end{tabular}

\section{DISCUSSÃO}

No contexto particular de análise, o ambiente portuário, o uso de drogas pode implicar risco à saúde e à vida do próprio trabalhador/usuário e dos seus colegas, tendo em vista que todos realizam seu trabalho no mesmo ambiente ou em um muito próximo. Entre os TPAs entrevistados, 43,14\% afirmaram que seus colegas já trabalharam sob efeito de drogas. Este percentual pode ser maior e estar atrelado ao fato de que o uso de drogas ainda é um tema estigmatizado na atual conjuntura da sociedade brasileira. Portanto, deve ser compreendido e tratado como um problema que é condicionado pelos distintos ambientes nos quais as pessoas que as usam se inserem, ou seja, depende da cultura de cada núcleo social, o que facilita ou não o acesso e o consumo destas substâncias.

0 uso das drogas ilícitas, em particular, possuem leis que 0 condenam, porém o grupo social do usuário o aprova ${ }^{6}$, o que também pode estar associado ao resultado obtido neste estudo. Neste sentido, o debate acerca desta problemática deve estar inserido na realidade do usuário, para que as propostas de prevenção estejam contextualizadas, possibilitando a superação da estigmatização e um debate socialmente ampliado ${ }^{12}$. Assim, torna-se importante utilizar, neste contexto, o enfoque da redução de danos, demonstrando ao TPA/usuário que não somente a sua segurança e vida podem estar comprometidas pelo uso de drogas, mas também a de seus colegas. Isso faz com que o trabalhador se responsabilize por si e por outros TPAs, entendendo, dessa maneira, que o uso de drogas, neste cenário tão particular, pode representar um dos limites para a saúde e a segurança de todos os envolvidos na operação portuária.

Os dados obtidos neste estudo apontam que o álcool foi a droga mais utilizada no ambiente portuário, assim como por $78,7 \%$ trabalhadores da indústria ${ }^{13}$. 0 alcoolismo relacionado ao trabalho pode ser uma prática defensiva utilizada pelos trabalhadores como forma de inclusão social ou como uma maneira de viabilizar o próprio trabalho. É uma droga utilizada com maior freqüência em ocupações cuja principal característica é o desprestígio social e em situações de trabalho perigoso $^{14}$. 0 contexto de trabalho portuário, que em sua essência possui muitos riscos, comprova, através desta pesquisa, o anteriormente referido. Além disso, o álcool é, das drogas pesquisadas neste estudo, a única aceita socialmente, ou seja, a admissão do uso desta pelos colegas de trabalho não representa um estigma para o grupo, tampouco uma ameaça. 
0 uso do álcool para viabilizar o trabalho graças aos efeitos farmacológicos obtidos: calmante, euforizante, estimulante, relaxante, indutor do sono, anestésico ${ }^{14}$, pode representar um risco a mais no contexto portuário, não se devendo esquecer que o risco é decorrente da decisão livre e consciente de se expor a uma situação, objetivando a concretização de um bem ou um desejo, podendo implicar a perda ou ferimento físico, material ou psicológico ${ }^{4}$.

Este sentido de risco pode ser assumido somente pelo trabalhador/usuário, e não por seus colegas que não fizeram uso desta substância, e, portanto, sua decisão não foi livre e consciente, já que não se escolhe no porto com quem se irá ou não trabalhar. Assim, há a necessidade de contemplar que o uso do álcool por alguns trabalhadores pode implicar um risco assumido involuntariamente por outros, podendo ocasionar situações indesejadas para todos, tendo em vista que os riscos à saúde e à vida no contexto portuário não são sempre os mesmos, porque distintos são os navios e as cargas que se apresentam no porto, com exigências de procedimentos de segurança peculiares a cada operação.

Neste trabalho, encontrou-se a maconha como a segunda droga referenciada como de utilização pelos colegas do entrevistado. Esta possui distribuição de uso por trabalhadores em todas regiões brasileiras, o que pode ser explicado pela facilidade de acesso à droga, por ser cultivada nas regiões norte e nordeste brasileiras, bem como em outros países da América do Sul ${ }^{15}$, sendo a droga ilícita mais utilizada na população de estudantes da cidade de Campinas ${ }^{16}$.

A maconha, pelas suas propriedades farmacológicas que tendem a relaxar e deixar o usuário em estado introspectivo, pode contribuir para a intensificação dos riscos à saúde e à vida no contexto portuário. Para a redução de danos em relação à maconha e dos riscos ocasionados pelo seu uso, fazem-se necessários o diálogo aberto entre todos os TPAs e o profissional de saúde; e a construção coletiva de possibilidades que permitam a diminuição de seu uso antes/durante o trabalho, enfatizando a importância da abstinência para a sua realização e sempre respeitando a cultura dos trabalhadores, dado que o risco é incessantemente construído e negociado como fator constituinte de uma rede de trocas sociais e de construção de sentidos ${ }^{17}$.

0 motivo principal apontado para o uso de drogas pelos colegas, a dependência, além de demonstrar a importância das ações de redução de danos no ambiente portuário, representa um limite, pois o presente estudo não visou apreender a existência de um diagnóstico ou se esta constatação se trata de senso comum. Entendendo que a dependência química, enquanto doença, possui natureza biológica, psicológica e social ${ }^{18}$, o OGMO, através do serviço de Assistência Social, encaminha os trabalhadores que 0 procuram, através de demanda espontânea, para um centro de referência em drogas do município. Conforme dados obtidos junto ao serviço, foram encaminhados para tratamento, no período de março a outubro de 2007, quatro TPAs.

0 pequeno número de encaminhamentos de trabalhadores para o serviço de referência demonstra a importância da realização de ações por parte da universidade no ambiente portuário, visando à prevenção. As aç̃̃es de prevenção primária são aquelas que procuram evitar o início do uso e o abuso de psicotrópicos. A prevenção secundária procura evitar a ocorrência de complicações para aqueles que fazem uso eventual de drogas e que apresentam poucos problemas. Já a terciária busca, a partir da detecção de um problema, evitar prejuízos adicionais e/ou reintegrar à sociedade as pessoas com problemas sérios ${ }^{19}$.

0 TPA/usuário que inicialmente pode ter usado drogas para socialização, por curiosidade, prazer ou para esquecer os problemas, tornou-se dependente da substância. Portanto, se faz necessária a compreensão de que "o desejo e o prazer com a droga vão substituindo todos os outros desejos e prazeres, e sua busca é marcada pela impulsividade e urgência de satisfação" 20:705. A ênfase nesta situação tão particular e individual deve estar na orientação e no aconselhamento no sentido de avaliação e discussão acerca das implicações do uso de drogas na vida diária do trabalhador, dentro e fora do ambiente de trabalho, a fim de definir com o TPA as possibilidades existentes para a diminuição dos danos ocasionados e aumento de sua qualidade de vida, bem como da de todos os que com ele convivem, incluindo os colegas de trabalho.

Além do trabalho com o indivíduo, faz-se necessário o trabalho coletivo, envolvendo todos os TPAs, por se entender que 0 uso e a dependência são influenciados pelo meio no qual o indivíduo se insere. Assim, torna-se relevante o esclarecimento acerca das implicações deste uso, não somente como risco no ambiente de trabalho, mas também como risco para a vida social do trabalhador, ressaltando a importância do apoio para os colegas que sentem a necessidade de reduzir os danos ou não mais usar drogas.

Neste sentido, é necessário reconhecer que o encontro do profissional enfermeiro com outro, com um sujeito de sua própria história, passa pelo conhecimento de que o uso de drogas é prazeroso, mas que pode trazer risco ao indivíduo e às coletividades nas quais estes se inserem, seja em âmbito familiar ou ocupacional.

$\mathrm{Na}$ especificidade do ambiente de trabalho, algumas empresas brasileiras adotam o programa de testes à procura por drogas no organismo dos trabalhadores, com a finalidade de oferecer programas de reabilitação e adotar medidas disciplinares ${ }^{15}$. Porém, a reabilitação e as medidas disciplinares nem sempre são efetivas quando as drogas podem ser obtidas nas proximidades do ambiente de trabalho, como é o caso do contexto portuário, viabilizando que o trabalhador as use e trabalhe sob seu efeito.

Assim, o estar sob o efeito da droga pode representar um risco à saúde e à vida do trabalhador/usuário e de seus colegas, particularmente em contextos onde se observam tanto 0 trabalho manual quanto 0 automatizado, como é 0 caso do trabalho portuário avulso. Destarte, precisa-se urgentemente de intervenções seguras no ambiente para a redução de danos ocasionados pelo uso de drogas ${ }^{21}$.

Este estudo possui o seu limite por se tratar da observação e levantamento de dados referentes ao uso de drogas em um microambiente, 0 ambiente portuário. Assim, faz-se necessário o aprofundamento da temática uso de drogas neste contexto, bem como em outros microespaços de trabalho, o que permitirá conhecer outras drogas utilizadas, o significado do uso, outros motivos que viabilizam a ocorrência do fenômeno no ambiente de trabalho portuário e em outros contextos. 


\section{CONCLUSÕES}

Este estudo permitiu concluir que existe o risco à saúde e à segurança relacionado ao trabalhar sob efeito de drogas no ambiente portuário. Entre as drogas citadas, destaca-se o uso do álcool e da maconha, e a dependência como motivo para a sua utilização.

A Enfermagem possui significante papel a ser desenvolvido enquanto mediadora e facilitadora no processo referente à diminuição do uso de drogas no ambiente de trabalho, e este estudo pode colaborar neste sentido. 0 conhecimento da realidade do usuário de drogas e a preocupação com o uso

\section{Referências}

1. Stein AS. Curso de Direito Portuário: lei nº 8630/93. São Paulo (SP); LTr; 2002.

2. Spricigo JN, Alencastre MB. 0 enfermeiro de Unidade Básica de Saúde e o usuário de drogas-um estudo em Biguaçú(SC). Rev. Latinoam Enfermagem 2004 mar/abr; 12 (n esp): 427-32.

3. Vásquez EM, Pillon SC. La formación de enfermeras y el fenónemo de lãs drogas em Colombia: conocimientos, actitudes y creencias. Rev. Latino-am Enfermagem 2005 set/out; 13 (n esp): 845-53.

4. Schenker M, Minayo MCS. Fatores de risco e proteção para o uso de drogas na adolescência. Cienc Saude Colet 2005 set; 10 (3): 707-17.

5. Nardi HC, Rigoni RQ. Marginalidade ou cidadania? A rede discursiva que configura o trabalho dos redutores de danos. Psicol Est 2005 maio/ago; 10 (2): 273-82.

6. Marinho MB. 0 demônio nos "paraísos artificiais": considerações sobre as políticas de comunicação para a saúde relacionadas ao consumo de drogas. Interface-comunicação, saúde, educação 2005 mar/ago; 9 (17): 343-54.

7. Carraro TE, Rassol GH, Luis MAV. A formação do enfermeiro e o fenômeno das drogas no sul do Brasil: atitudes e crenças dos estudantes de enfermagem sobre o cuidado. Rev Latino-am Enfermagem 2005 set/out; 13 (n esp): 863-71.

8. Decreto $n^{0} 4.345$, de 26 de agosto de 2002. Institui a Política Nacional Antidrogas e dá outras providências. Diário Oficial da República Federativa do Brasil, Brasília (DF), 27 de agosto de 2002. Seção 1:3.

9. Carvalho FE. Trabalho portuário avulso: antes e depois da lei de modernização dos portos. São Paulo (SP): LTr; 2005.

10. Silveira FL. Relação do desempenho no concurso vestibular da Universidade Federal do Rio Grande do Sul com diversas variáveis: Estud Avaliacao Educ 1996 jul/dez; 14: 83-103.

11. David HMSL, Caufield C. Mudando o foco: um estudo exploratório sobre uso de drogas e violência no trabalho entre mulheres das classes populares da cidade do Rio de Janeiro, Brasil. Rev Latino-am Enfermagem 2005 nov/dez; 13 (n esp): 1148-154.

12. Laranjo THM,Soares CB. Moradia universitária: processos de socialização e uso de drogas. Rev Saude Publica 2006 dez; 40 (6): 1027-34.

13. Serviço Social da Indústria -SESI. Levantamento sobre o uso de drogas na indústria. s/d [citado 03 nov 2007]. Disponivel em: http:// obid.senad.gov.br/OBID/Portal/conteudo.jsp?ldPJ=4402\&ldEC=6234

14. Ministério da Saúde (Br). Doenças relacionadas ao trabalho: manual de procedimentos para os serviços de saúde. Brasília (DF); 2001.

15. Silva A0, Yonamine M. Drug abuse among workers in Brazilian regions. Rev. Saúde Pública 2004 ago; 38 (4): 552-56. em ambientes de trabalho tornam-se ferramentas importantes para o enfermeiro, posicionando-o como colaborador e parceiro na sensibilização dos indivíduos para a diminuição dos riscos decorrentes do uso de drogas na vida do trabalhador e no ambiente de trabalho.

Trata-se de o enfermeiro visualizar o ambiente de trabalho como um todo, não somente estabelecendo o seu foco nos riscos ocupacionais clássicos, tais como os ruídos, mas colocando o seu olhar principalmente sobre o trabalhador e as suas ações, o que possibilitará a diminuição do uso de drogas e o aumento da segurança e da saúde não somente no trabalho portuário, mas nas mais distintas realidades ocupacionais.

16. Soldera M, Dalgalarrondo P, Corrêa Filho HR, Silva CAM. Uso de drogas psicotrópicas por estudantes: prevalência e fatores associados. Rev Saude Publica 2004 abr; 38 (2): 277-83.

17. CarvalhoSR. As contradições da promoção à saúde em relação à produção de sujeitos e mudança social. Cienc Saude Colet 2004 jul/set; 9 (3): 669-78.

18. Organização Pan-Americana de Saúde-OPAS. Comissão Interamericana para o Controle do Abuso de Drogas-CICAD. EI tratamiento de los problemas relacionados con la dependencia de las drogas. In: La dependencia de las drogas y su tratamiento - guia y criterios básicos para el desarrollo de programas de avaluación de la calidad y normas para la atención de la dependencia de drogas. Washington (USA); 2000.

19. Organização Mundial da Saúde-OMS. Reagindo aos problemas das drogas e do álcool na comunidade. São Paulo(SP); 1992.

20. Farias FLR, Furegato ARF. 0 dito e o não dito pelos usuários de drogas, obtidos mediante as vivências e da técnica projetiva. Rev. Latino-am Enfermagem 2005 set/out; 13 (5): 700-07.

21. Rhodes T, Kimber J, Small W, Fitzgerald J, Kerr T, Hickman M et al. Public injecting and the need for 'safer environment interventions' in the reduction of drug-related harm. Addiction 2006 0ct; 101 (10):1384-393.

\section{Notas}

Trabalho integrante do macroprojeto de pesquisa "Saúde do trabalhador e conhecimento sobre situações de risco: um estudo com trabalhadores portuários avulsos do município do Rio GrandeRS" sob responsabilidade da pesquisadora Marta Regina Cezar-Vaz.

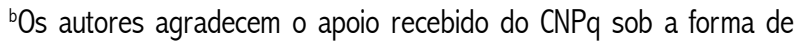
concessão da bolsa de Iniciação Científica de Letícia Silevira Cardoso e de financiamento do macroprojeto "Saúde do trabalhador e conhecimento sobre situações de risco: um estudo com trabalhadores portuários avulsos do município do Rio Grande-RS" (Processo n²85227/2006-1- auxílio 2006/2008). Agradecem também à FAPERGS pela concessão da bolsa de Iniciação Científica de Marlise Capa Verde de Almeida.

\section{Autora}

\section{Ana Luiza Muccillo-Baisch}

Enfermeira. Doutora em Biologia da Saúde. Professora Associada do DCF da FURG Rio Grande-RS. 